
allemande

50-2 | 2018

Humanités environnementales - Quoi de neuf du côté des méthodes?

\title{
La clause de non-concurrence au sein du contrat de travail : droit allemand et droit français se démarquent
}

chronique juridique

Sandie Calme

\section{(2) OpenEdition}

Journals

Édition électronique

URL : https://journals.openedition.org/allemagne/1006

DOI : 10.4000/allemagne. 1006

ISSN : 2605-7913

Éditeur

Société d'études allemandes

Édition imprimée

Date de publication : 30 décembre 2018

Pagination : 457-461

ISSN : 0035-0974

Référence électronique

Sandie Calme, «La clause de non-concurrence au sein du contrat de travail : droit allemand et droit

français se démarquent », Revue d'Allemagne et des pays de langue allemande [En ligne], 50-2 | 2018, mis en ligne le 30 décembre 2018, consulté le 18 mai 2021. URL : http://journals.openedition.org/ allemagne/1006 ; DOI : https://doi.org/10.4000/allemagne.1006 


\title{
Chronique juridique
}

\section{La clause de non-concurrence au sein du contrat de travail: droit allemand et droit français se démarquent}

\author{
- Sandie Calme*
}

Une clause de non-concurrence est fréquemment insérée au sein du contrat de travail, jugée nécessaire afin de préserver la pérennité de l'entreprise d'accueil du salarié. Cette clause est encadrée par de strictes conditions de validité ainsi qu'une régulation des conséquences indemnitaires en contrepartie de l'existence de l'obligation de non-concurrence.

Si la clause de non-concurrence n'est pas obligatoire au sein des dispositions du contrat de travail, elle se retrouve en pratique de façon récurrente parmi les dispositions du contrat de travail, de droit allemand comme de droit français. Les dispositions qui régissent sa validité ainsi que ses suites indemnitaires dépendent de la question clé de la loi applicable, droit français ou droit allemand par exemple, en particulier dans les relations individuelles de travail présentant un ou plusieurs éléments d'extranéité. On pense notamment au travail dit international.

La jurisprudence allemande s'est récemment saisie de la question de la validité et de l'indemnisation de la clause de non-concurrence, se distinguant des solutions retenues en droit français par la chambre sociale de la Cour de cassation. C'est le tribunal fédéral du travail allemand qui a tranché, en appelant l'attention sur l'enjeu de la loi applicable.

Par un arrêt de rejet en date du 31 janvier 2018 (10 AZR 392/17), la dixième chambre du tribunal fédéral du travail allemand a jugé que les dispositions relatives au droit de retrait légal des articles $\$ \$ 323$ et suivants du Code civil allemand ne s’appliquent pas aux interdictions de concurrence post-contractuelles régies par les articles $\$ 110$ de la l'ordonnance allemande GewO et $\$ \$ 74$ et suivants du Code de commerce à l'issue de

* Avocate au barreau de Paris, LL.M. (Francfort sur le Main). 
la relation de travail. Le tribunal précise que l'article $\$ 314 \mathrm{du}$ Code civil allemand ne contrevient pas à cette règle.

Dans cet arrêt de rejet, le tribunal fédéral du travail allemand va dans le sens de la position adoptée par la Cour d'appel, ce qui explique que les frais de justice sont laissés à la charge du demandeur au pourvoi.

En l'espèce, les parties s'opposaient sur une question de versement de l'indemnité compensatrice de clause de non-concurrence.

L'indemnité était ajustée dans son montant à la capacité financière de l'employé sur la durée d'application de la clause, de sorte que, suite à un licenciement ordinaire au 31 janvier 2016, l'employé percevait une allocation de chômage, mais aucune indemnité au titre de la clause de non-concurrence.

Suite à des relances, l'employé écrivait par courriel, le 8 mars 2016, à son ancien employeur, qu'il ne se considérait plus, dans l'immédiat, comme tenu à la clause de non-concurrence.

En première instance, l'employé obtenait du tribunal l'indemnité sollicitée, sur la base des trois mois contractuels. Toutefois, en appel, il n'était fait droit que partiellement à sa demande, le Landesarbeitsgericht lui refusant désormais la quote-part d'indemnité pour la période du 9 mars au 30 avril 2016. L'employé argumentait dans le sens du retour à la décision de première instance en se prévalant de la mauvaise foi de l'employeur et du fait qu'il avait de facto respecté l'obligation de non-concurrence pour toute la durée de validité contractuelle de la clause.

L'employé, qui était libre de disposer de sa force de travail et d'exercer une activité concurrente à l'issue de son retrait, avait valablement procédé à ce dernier par son courriel, sans pour cela qu'il soit nécessaire de se référer au motif du retrait.

Ainsi, le tribunal fédéral du travail venait à l'appui de l'arrêt d'appel: l'obligation indemnitaire et la renonciation à la concurrence étaient dans une relation de réciprocité et les obligations mutuelles y afférentes étaient éteintes dès le 9 mars 2016.

L'arrêt met l'accent sur le caractère contractuel des engagements souscrits et met en valeur l'impact du courriel au sein des relations contractuelles, considéré comme un véritable écrit qui a toute sa place au cœur du contrat.

La clause de non-concurrence sera ainsi soumise à un régime juridique différent selon qu'elle est régie, par exemple, par le droit français ou par le droit allemand. Dans le cadre dit intracommunautaire, la différence se justifie par la problématique de la détermination de la loi applicable au contrat de travail, qu'elle soit choisie ou résultant de l'implication du droit de l'Union européenne. Cela pose la question de l'existence et de la validité du choix de loi ainsi que celle de la sécurité juridique en matière de travail transnational. Le quantum de l'indemnité est également une différence liée à la détermination de la loi applicable.

Les concepts qui sous-tendent les mécanismes d'obligation de non-concurrence au sein du contrat de travail relèvent de considérations philosophiques analogues, mais le régime juridique de base est en pratique différent, avec notamment une évolution jurisprudentielle qui peut être qualifiée d'indépendante. 


\section{Clause de non-concurrence: droit allemand versus droit français du travail}

La clause de non-concurrence de droit allemand relève d'un régime distinct de celui du droit français: cette démarcation est mise en lumière par la jurisprudence récente.

\section{A. Le mécanisme de la clause de non-concurrence en droit allemand du travail}

Les contours de la clause de non-concurrence de droit du travail allemand sont, à la base, classiques, d'un point de vue conceptuel. Toutefois, c'est dans le détail de la réglementation et de la jurisprudence que se révèle une relativement large distinction.

La clause de non-concurrence se définit en droit allemand comme un accord entre employeur et employé visant à limiter l'activité professionnelle de l'employé pour un certain temps à compter de la fin de la relation de travail (article $\$ 110$ de l'ordonnance Gewerbeordnung). Cette disposition précise que les articles $\$ \$ 74$ à $75 \mathrm{f}$ du Code de commerce allemand s'appliquent en conséquence.

Ces dispositions prévoient la forme écrite nécessaire de la clause (article $\$ 74$ alinéa $1^{\text {er }}$ du Code de commerce allemand), le caractère impératif du versement d'une indemnité pour toute la durée de la clause, avec un montant annuel de la moitié des dernières prestations contractuelles du travailleur (article $\$ 74$ alinéa 2 ).

La sanction de la violation de cette norme indemnitaire est le caractère non avenu de la clause. Il en est de même si la clause ne sert pas à protéger un intérêt économique légitime de l'employeur, si les circonstances de fait, de temps ou de lieu entravent injustement les perspectives d'avenir de l'employé ou si l'interdiction excède la durée de deux ans à compter de la fin de la relation de travail (article $\$ 74$ a alinéa $1^{\text {er }}$ du Code de commerce).

D'autres circonstances d'ordre public conduisent à considérer la nullité de la clause (article $\$ 74$ a alinéa 2 du Code de commerce).

Si les facultés contributives de l'employé sont prises en compte dans le décompte de l'indemnité versée, cette prise en compte est restreinte (article $\$ 74 \mathrm{c}$ du Code de commerce).

En tout état de cause, le respect des bonnes mœurs est également applicable, selon l'article $\$ 138 \mathrm{du}$ Code civil allemand (article $\$ 74$ a alinéa 3 ).

Cependant, le présent arrêt du tribunal fédéral du travail allemand rappelle la prégnance de la hiérarchie des normes dans le cadre contractuel, en mettant l'accent sur l'éviction des dispositions de droit commun (articles $\$ \$ 314$ et 323 et suivants du Code civil allemand).

En l'espèce, l'employé licencié s'était prévalu des normes de droit civil allemand, notamment au niveau de l'exigence de bonne foi dans les relations contractuelles et du droit à la résiliation immédiate de dispositions contractuelles pour raison majeure.

L’article $\$ 314$ du Code civil allemand permet la résiliation immédiate d'une relation contractuelle continue pour une raison importante, assortie de délais le cas échéant, tout en laissant ouverte la possibilité d'octroi de dommages et intérêts.

Dans le même esprit, les articles $\$ \$ 323$ et suivants du Code civil organisent la faculté de rétractation de la relation contractuelle. 


\section{B. Les spécificités du droit français}

Les conditions de validité et d'indemnisation de la clause de non-concurrence se distinguent en droit français, sur fond de considérations d'ordre public: à peine de nullité, la clause de non-concurrence doit être à la fois limitée dans le temps et dans l'espace, indispensable pour la protection des intérêts légitimes de l'employeur, adaptée aux spécificités de l'emploi en cause, et effectivement compensée par une indemnité.

À ce niveau, la problématique porte sur la teneur de l'indemnisation, qui peut, en droit français, être réduite à néant même en présence d'une violation par l'employeur des exigences propres à la clause de non-concurrence.

Par le passé, la jurisprudence de la Cour de cassation, en droit français, décidait que «le respect par le salarié d'une clause de non-concurrence illicite lui cause nécessairement un préjudice dont il appartient au juge d'apprécier le montant». En cela, cette ancienne jurisprudence rejoignait la conception jurisprudentielle actuelle du tribunal fédéral du travail allemand (Cass. soc., 15 novembre 2006, pourvoi nº 04-46721, publié au Bulletin). Il y avait donc une garantie d'indemnisation au salarié qui se pliait à une clause de non-concurrence souscrite en violation de ses droits. Ainsi, c'était le respect de la clause illicite qui fondait le droit a priori systématique à une indemnité accordée à l'employé qui quittait l'entreprise. De la sorte, la solution jurisprudentielle de droit allemand comportait une certaine équivalence fonctionnelle avec celle du droit français.

Toutefois, avec un arrêt de 2016, la Cour de cassation française se distingue par un revirement de jurisprudence disposant que (Cass. soc., 25 mai 2016, pourvoi $\mathrm{n}^{\circ}$ 14-20578, publié au Bulletin) dès lors que les juges du fond concluent que le salarié ne subit aucun préjudice résultant de l'illicéité de clause de non-concurrence, il y a lieu de retenir que l'existence d'un préjudice et l'évaluation de celui-ci relèvent du pouvoir souverain d'appréciation des juges du fond. Ainsi, l'indemnisation n'est pas de droit et relève de l'appréciation de considérations de fait.

En conséquence, présentement, en droit français, pour ce type de situation, l'indemnité éventuelle se traduit en principe en l'octroi de dommages et intérêts. Toutefois, le salarié qui n’a subi aucun préjudice résultant de l'illicéité de la clause de non-concurrence ne saurait bénéficier d'une indemnisation à ce titre, dans la mesure où l'existence d'un préjudice et l'évaluation de celui-ci relèvent du pouvoir souverain d'appréciation des juges du fond (Cass. soc., 25 mai 2016, pourvoi no 14-20578).

\section{La question de la loi applicable}

La question de la loi applicable à la clause de non-concurrence représente un enjeu important.

Dans le contexte franco-allemand, le règlement (CE) n $n^{\circ}$ 593/2008 du Parlement européen et du Conseil du 17 juin 2008 sur la loi applicable aux obligations contractuelles (Rome I) explicite l'enjeu.

Dans le cadre dit intracommunautaire, ce règlement permet le choix de la loi applicable à la relation contractuelle, ce qui influe sur le régime juridique de la clause de non-concurrence. 
En outre, ce règlement détermine, à défaut de choix ou de choix valable, quelle doit être la loi applicable au contrat de travail, de sorte que l'ensemble de la relation contractuelle peut être régi par un droit national distinct sur des considérations contractuelles.

À propos du contrat de travail, ce règlement donne la primauté au choix de la loi applicable sous réserve de certaines considérations d'ordre public.

Faute de choix, des alternatives s'appliquent en cascade: loi du pays d'accomplissement habituel du travail, loi du pays de l'établissement qui a embauché le travailleur, liens plus étroits avec tel ou tel pays selon l'ensemble des circonstances (article $8 \mathrm{du}$ Règlement).

Il y a donc une marge d'appréciation relativement importante en considération d'éléments factuels: par exemple, accomplissement du travail au sein de plusieurs pays, emploi par une multinationale, circonstances particulières de lien étroit avec un pays parmi d'autres.

En somme, le présent arrêt du tribunal fédéral du travail allemand vient préciser la différenciation au niveau des conséquences indemnitaires de la clause de non-concurrence invalide en spécifiant que le cadre contractuel avéré de la relation d'obligation de non-concurrence post-contractuelle ne contrevient pas à l'application d'un régime juridique spécial distinct du cadre général du droit commun. L'analyse comparative des ordres juridiques allemand et français sur ce point permet de souligner que l'indemnisation relative à la clause de non-concurrence irrégulière peut être restreinte dans son montant ou même inexistante en l'absence de préjudice comme à défaut de respect de cette clause. 